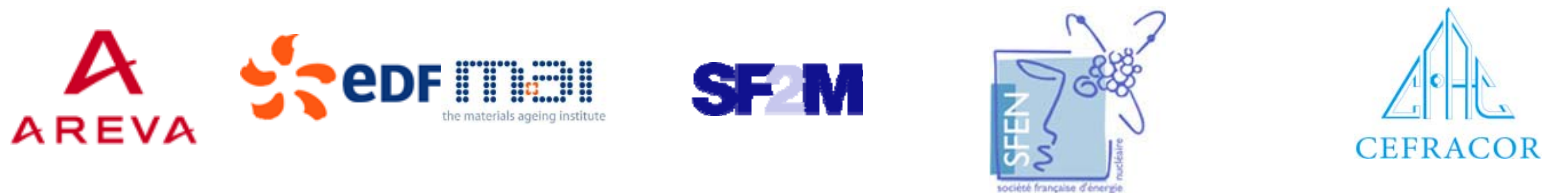

\section{MIN口S}

Centre of Excellence for Nuclear Materials

\section{Workshop}

Materials Innovation for Nuclear Optimized Systems
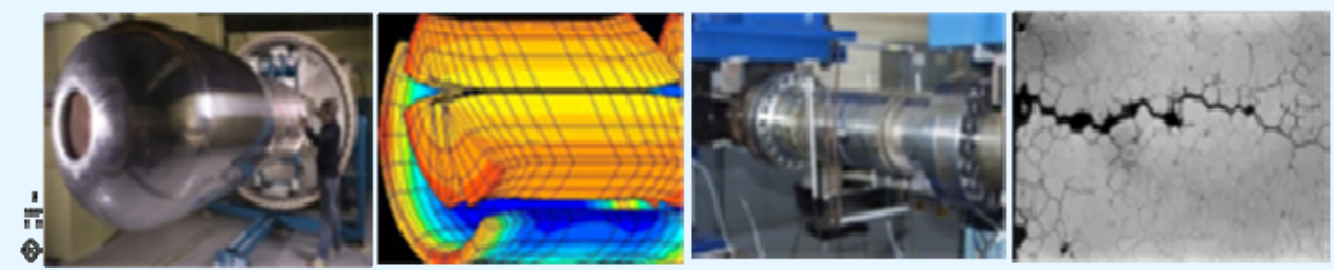

December 5-7, 2012, CEA - INSTN Saclay, France

\section{Patrick DAVID et al.}

CEA (France)

New Textile Structures and Film-Boiling Densification for $\mathrm{SiC} / \mathrm{SiC}$ Components

Workshop organized by:

Christophe GALLÉ, CEA/MINOS, Saclay - christophe.galle@cea.fr Constantin MEIS, CEA/INSTN, Saclay - constantin.meis@cea.fr 


\title{
New Textile Structures and Film-Boiling Densification for SiC/SiC Components
}

\author{
Patrick DAVID ${ }^{1}$, Joelle BLEIN ${ }^{1}$, Yannick PIERRE ${ }^{1}$, Denis ROCHAIS ${ }^{1}$, Maxime ZABIEGO ${ }^{2}$ \\ ${ }^{1}$ CEA-DAM, Département Matériaux (Monts, France) \\ ${ }^{2}$ CEA-DEN-DEC, Service d'Etudes et de Simulation du Comportement des Combustibles, SESC (Cadarache, France)
}

Among all ceramic candidates, silicon carbide (SiC) materials present the best properties for use in very harsh nuclear environments. Indeed, they possess an excellent behavior under high neutron irradiation, high thermal conductivity and mechanical properties at high temperature in addition to a chemical inertness. Meanwhile, as monolithic ceramics are too brittle, it is necessary to use SiC in the form of $\mathrm{SiC} / \mathrm{SiC}$ materials, which exhibit a high fracture toughness and allow the manufacturing of both very thin and large pieces. Principal studies of nuclear applications have been conducted since the middle of the 1990's, for blanket of wall fusion reactors [1]. SiC/SiC composites have also been recently envisaged as alternatives to zircaloy fuel claddings in order to cope with core overheating accidents of Light Water Reactors [2]. During the last decade, intensive investigations on $4^{\text {th }}$ generation fission reactor applications have been conducted [3], mainly for fuel claddings, and also, more recently, for other components, such as the Hexagonal Tube (HT) for pin assembling, control rods, heat exchangers or thermal barriers for the Hot Gas Duct.

Several developments and optimizations are necessary to meet the specifications of structural components in nuclear systems which differ strongly from those of common aeronautical and spatial applications. The performed studies have addressed several technological points that were considered as bottlenecks. For Gas cooled Fast Reactor claddings, new textile processes have been developed for manufacturing of honeycomb structures [4] or closed tubular braids [5] (Figure 1), used as fibrous reinforcement structures. Control of the geometry can be improved using graphite tools, during densification, and by addition of a sacrificial layer that is machined away after densification (Table 1), (Figure 2). The internal surface smoothness has been increased through an initial Chemical Vapor Deposition step on the graphite rod used as a mandrel for pin braiding. As SiC/SiC materials possess a limited tolerance when it comes to the set deformation, a flexible ceramic porous bond, constituted of a ceramic textile structure, has been proposed [6] and characterized to improve the fuel pellet-clad interaction.

Concerning the Hexagonal Tube, studies have been performed on the very particular film-boiling process (Figures 3 and 4). The aim was to reduce the important densification time and cost, due to the quite large dimensions and thickness of this component. Depending on the chemical precursors used, the main difficulty consisted in controlling either the matrix composition, which can contain excess carbon, or the microstructure, which can be less ordered and conductive than CVI deposits. A few investigations have also been initiated on SiC/SiC with low density and conductivity, to manufacture a thermal barrier for the Hot Gas Duct.

Owing to the stringent specifications set for nuclear components, the development of SiC/SiC materials, and more particularly for cladding applications, is an ambitious target, both from technological and scientific standpoints. Complementary tests and characterizations are still necessary to prove that these materials are consistent with the targeted performance. All the knowledge and knowhow developed during these studies should be useful to obtain technological solutions for tailored and reliable $\mathrm{SiC} / \mathrm{SiC}$ components for high-temperature (nuclear) applications. 
(1-a)

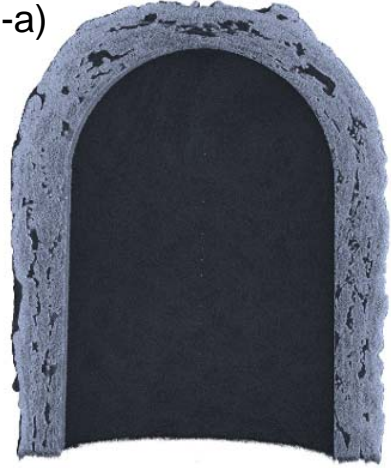

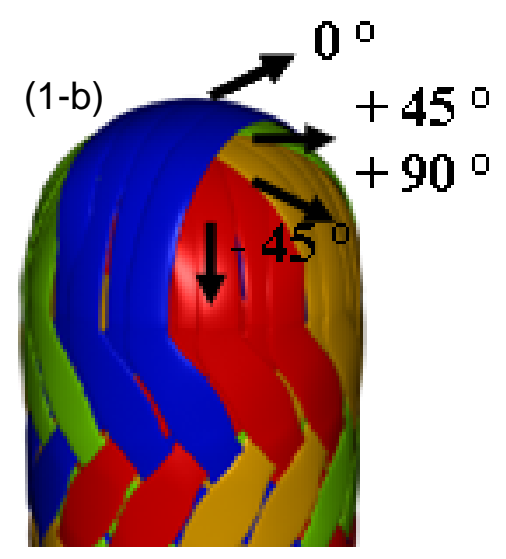

Fig. 1: The closed extremity of the SiC/SiC densified braid (1-a) and a representation (simulation) of the position of the yarns (1-b).

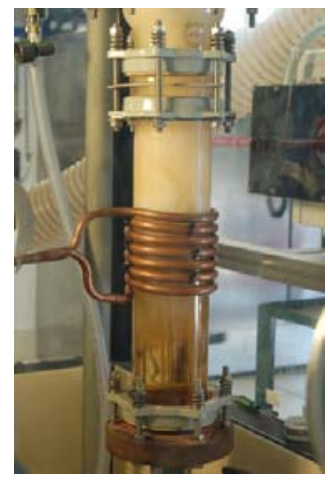

Fig. 3: A view of the film-boiling reactor. The fibrous structure is immersed in a liquid precursor and brought to about $1000^{\circ} \mathrm{C}$ through radio-frequency heating.

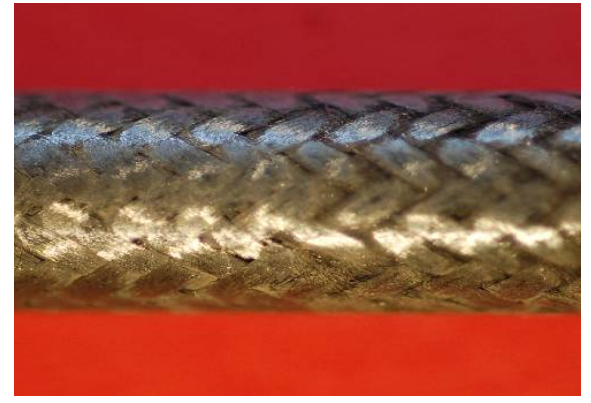

Fig. 2: A view of the surface of the SiC/SiC densified braid, after machining $(\mathrm{Ra} \sim 10 \mu \mathrm{m})$.

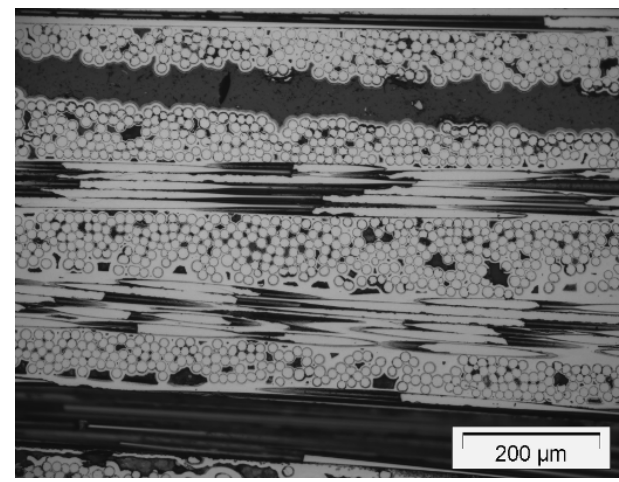

Fig. 4: The microstucture of a SiC/SiC composite (hexagonal tube application) densified with the film-boiling technique.

Table 1: Accuracies obtained for the geometrical dimensions of a 10-cm long, 4-layered bi-axial braid.

\begin{tabular}{|c|c|c|}
\hline External Diameter $(\mathrm{mm})$ & General straightness $(\mathrm{mm})$ & Local straightness $(\mathrm{mm})$ \\
\hline$[8.96,8.99]$ & $<0.03$ & 0.04 \\
\hline
\end{tabular}

\section{References}

[1] L.L. Snead, R.H. Jones, A. Kohyama, P. Fenici, Status of silicon carbide composites for fusion. J. Nucl. Mater. 233-237, 26 (1996).

[2] H. Feinroth, B. Hao, L. Fehrenbacher, Progress in developing an impermeable, high temperature ceramic composite for advanced reactor clad and structural applications. ICAPP Proceedings (2002).

[3] W. Corwin, The Gas Fast Reactor (GFR) Survey of Material Experience and R\&D Needs to Assess Viability. Ref: ONRL/TM-2004/99 (2004).

[4] CEA Patent, CEA Patent, Method for producing a cellular fibrous structure, P. David. WO 2009/0065794, 28/05/2009.

[5] CEA Patent, Architecture fibreuse tubulaire fermée et procédé de fabrication, P. David, JL Bonnand, B. Bompard, PCT/EP2010/067736, 18/11/2010.

[6] CEA Patent, Joint d'interface solide à porosité ouverte pour crayon de combustible nucléaire et pour barre de commande nucléaire. M. Zabiego, P. David, A. Ravenet, D. Rochais, PCT/EP2011/060001, 16/06/2011. 
DE LA RECHERCHE À L'INDUSTRIE
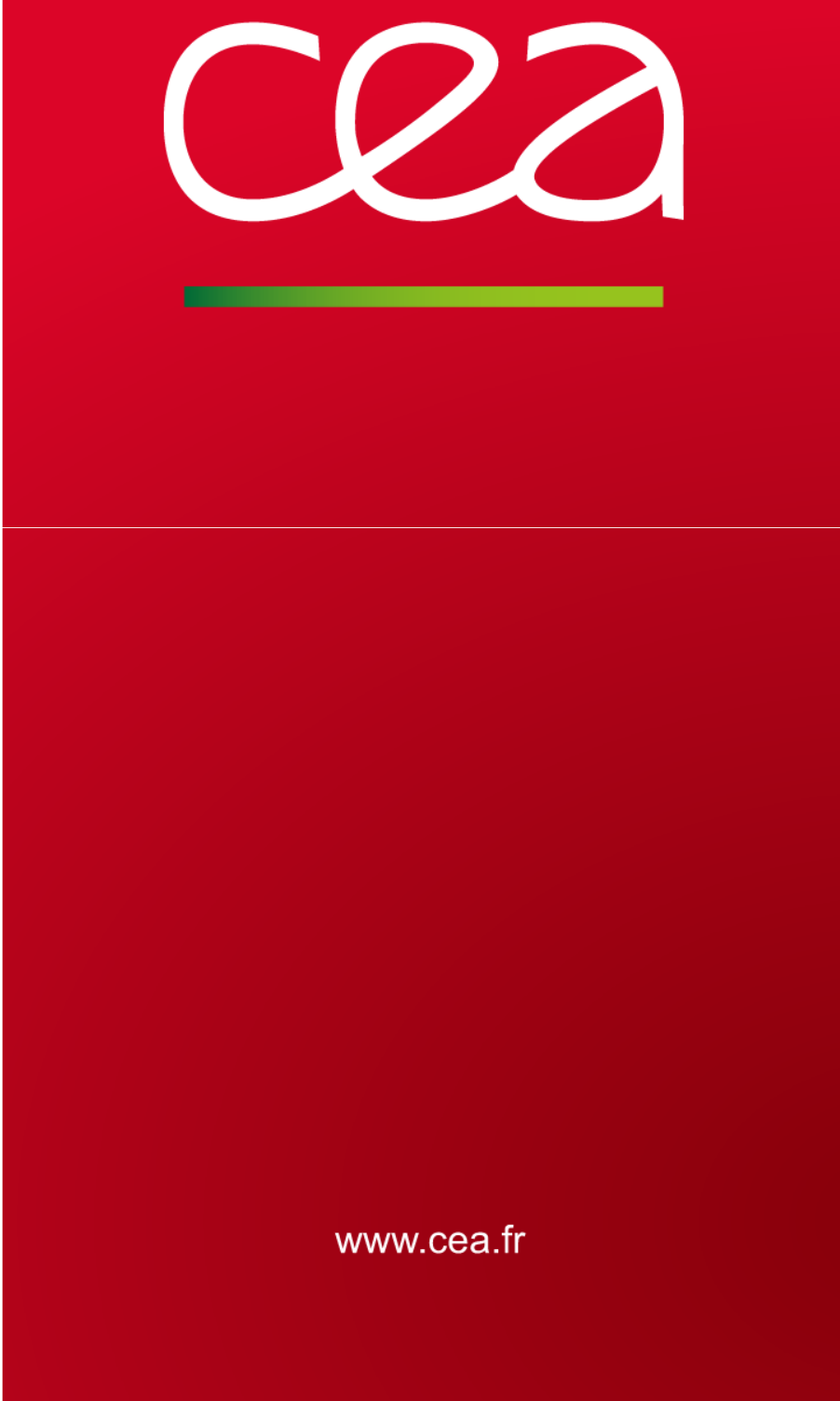

\section{NEW TEXTILE STRUCTURES AND FILM-BOILING DENSIFICATION FOR SIC/SIC COMPONENTS (IV Gen.)}

P. David ${ }^{1}$, J. Blein ${ }^{1}$, D. Rochais ${ }^{1}$, Y. Pierre ${ }^{1}$, M. Zabiego ${ }^{2}$

Commissariat à l'énergie atomique et aux énergies alternatives (CEA)

${ }^{1}$ Le Ripault, F-37260, Monts, France

${ }^{2}$ Cadarache, F-13108, Saint-Paul-lez-Durance, France

\section{Studies supervised by CEA/DEN}

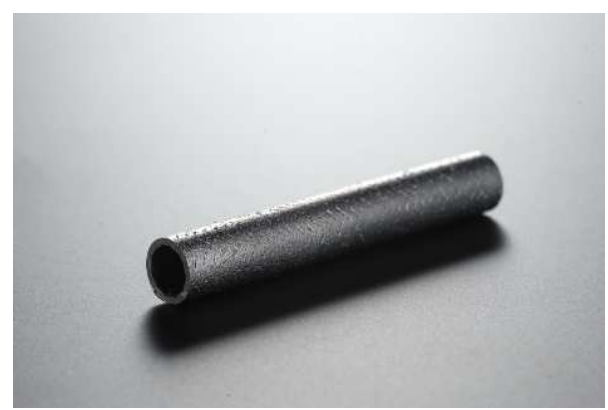

\section{MIN口S}

Workshop Materials Innovation for Nuclear Optimized Systems December 5-7, 2012,r.EA - INSTN Sichiy. Fiance 


\section{Cea PRESENTATION OUTLINE}

1- Generalities

2- Honeycomb

3- Pin, buffer

4- Hexagonal Tube (Film-Boiling densification)

5- Insulators

6- Conclusion 


\section{Cea 1-GENERALITIES : SiC/SIC APPLICATIONS}

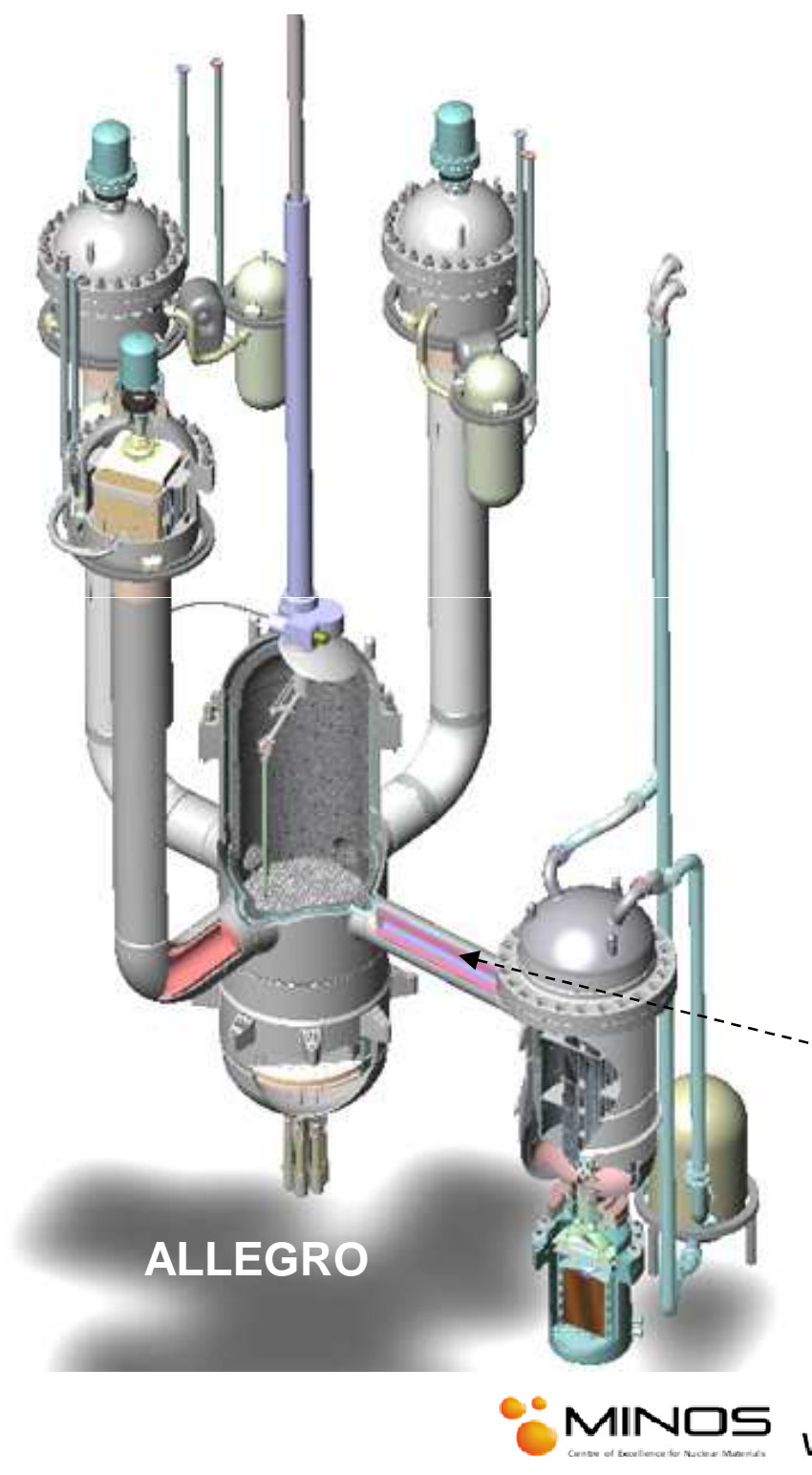

1- GFR Fuel claddings

$\mathrm{T} \sim 900^{\circ} \mathrm{C}, \mathrm{P}_{\mathrm{He}} \sim 70 \mathrm{bar}$

2 concepts
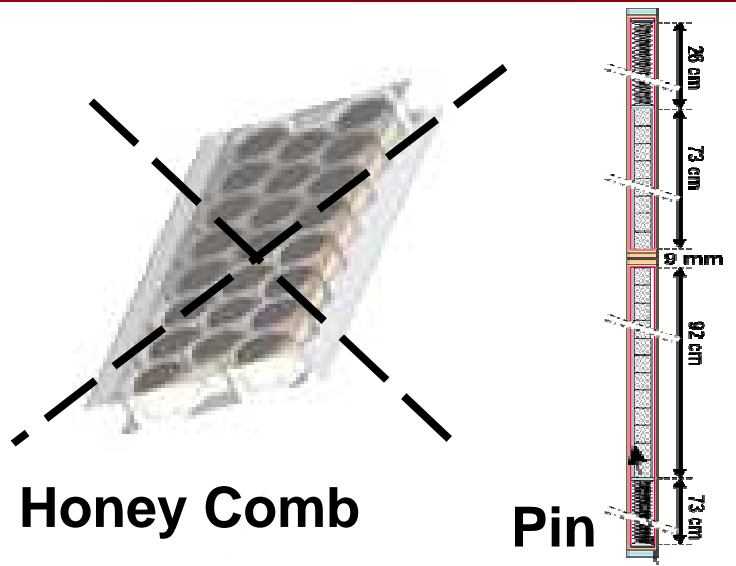

2- SFR Hexagonal tube $\mathrm{T} \sim 700^{\circ} \mathrm{C}$

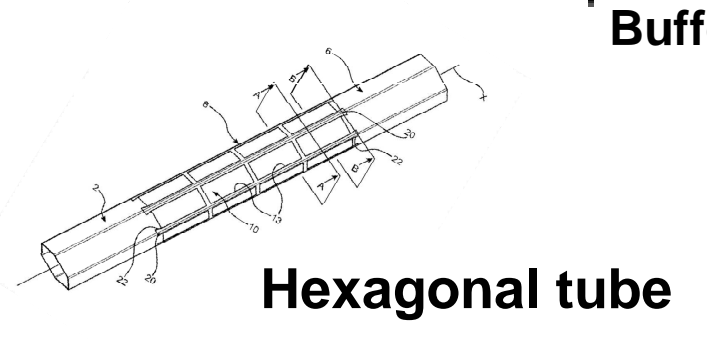

3- GFR Hot Gas Duct

$\mathrm{T} \sim 450^{\circ} \mathrm{C} / 850^{\circ} \mathrm{C}, \mathrm{P}_{\mathrm{He}} \sim 70 \mathrm{bar}, \mathrm{v}_{\mathrm{He}} \sim 40-70 \mathrm{~m} / \mathrm{s}$ Insulators

Other potential applications:

- WPR components with improved safety

- control rods, ... 
$\left.\begin{array}{l}\text {. Irradiation behaviour } \\ \text {. Mechanical behaviour } 900^{\circ} \mathrm{C}\end{array}\right\} \Rightarrow \mathrm{SiC} / \mathrm{SiC}$

$\sigma:$ as high as possible, $\varepsilon>0,5-1 \%$

. Thermal conductivity: as high as possible (>10 W/mK)

. Gas tightness (liner)

. Dimensional accuracy : better than $0.1 \mathrm{~mm}$

. Surface smoothness : Ra $<50 \mu \mathrm{m}$

. Closure system (two half pin concept)

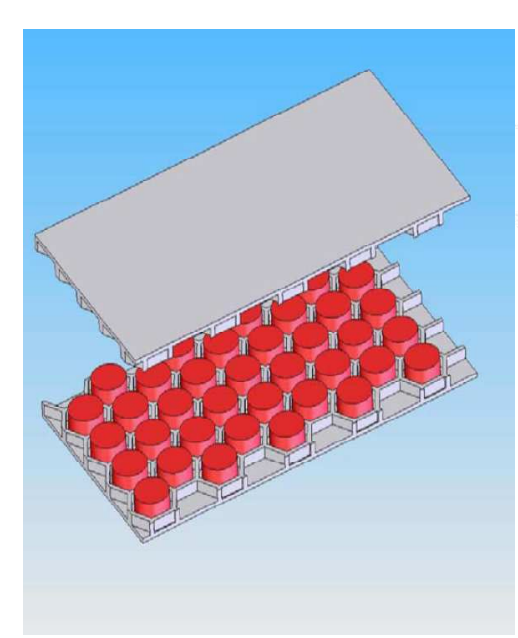

Ext. Across flat : $13 \mathrm{~mm}$ e (wall) : $1.3 \mathrm{~mm}$ $\mathrm{H}:$ 3-10 mm

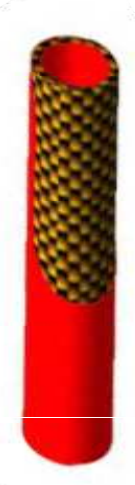

$\Phi_{\mathrm{nt}}: 7 ; 8 \mathrm{~mm}$

e : $1 \mathrm{~mm}$

$\mathrm{L}: \sim 1.5$ or $3 \mathrm{~m}$ 


\section{Cea 2- NEW PROCESS FOR HONEYCOMBS}

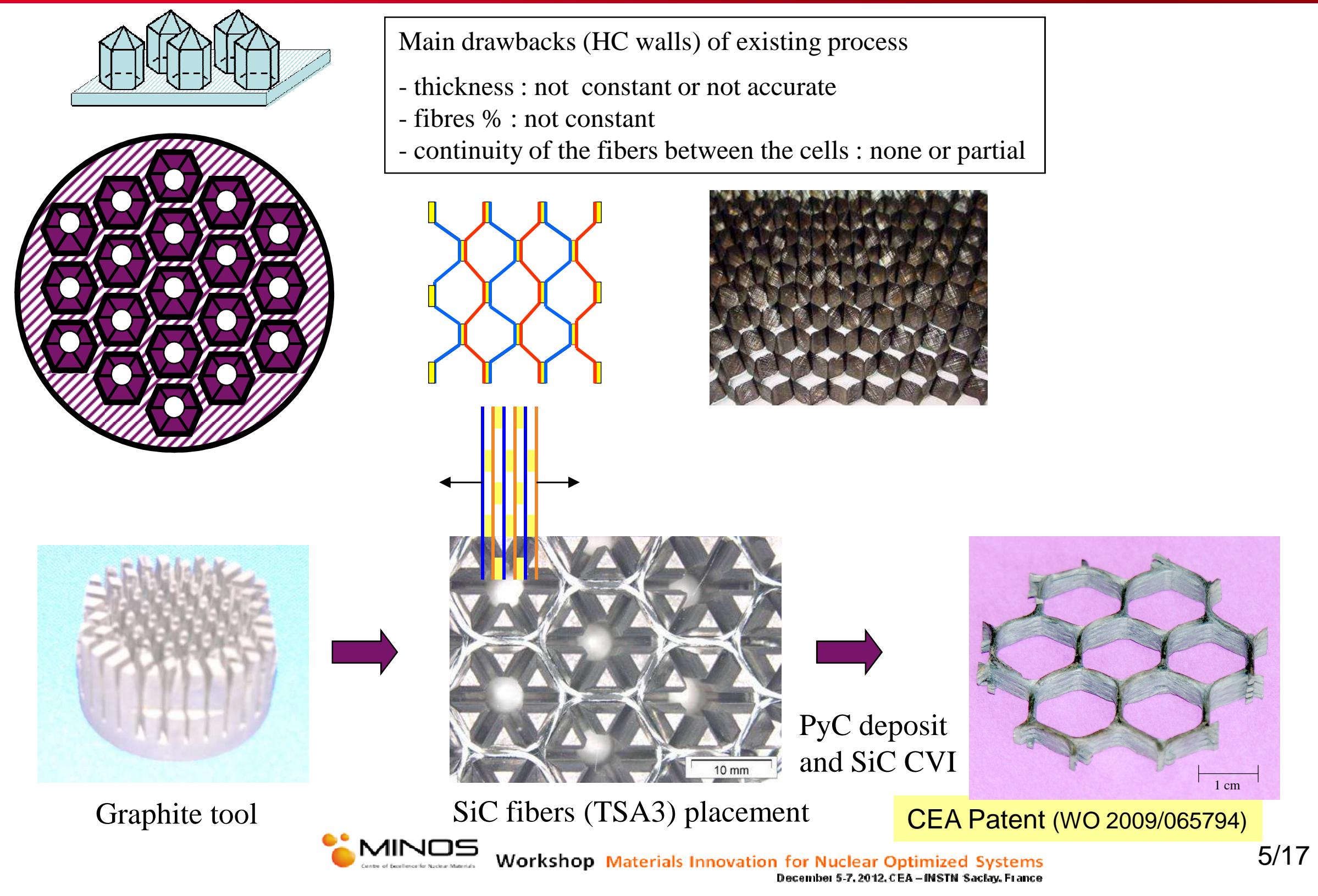




\section{CEA HONEYCOMBS CHARACTERIZATION}

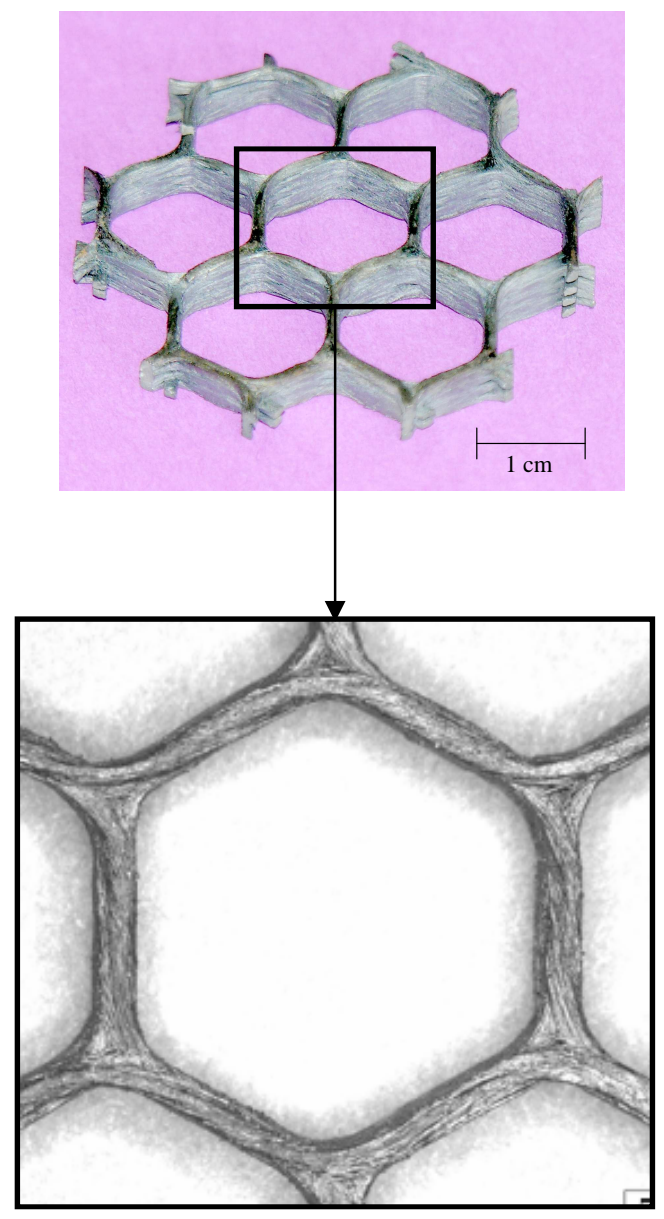

Results

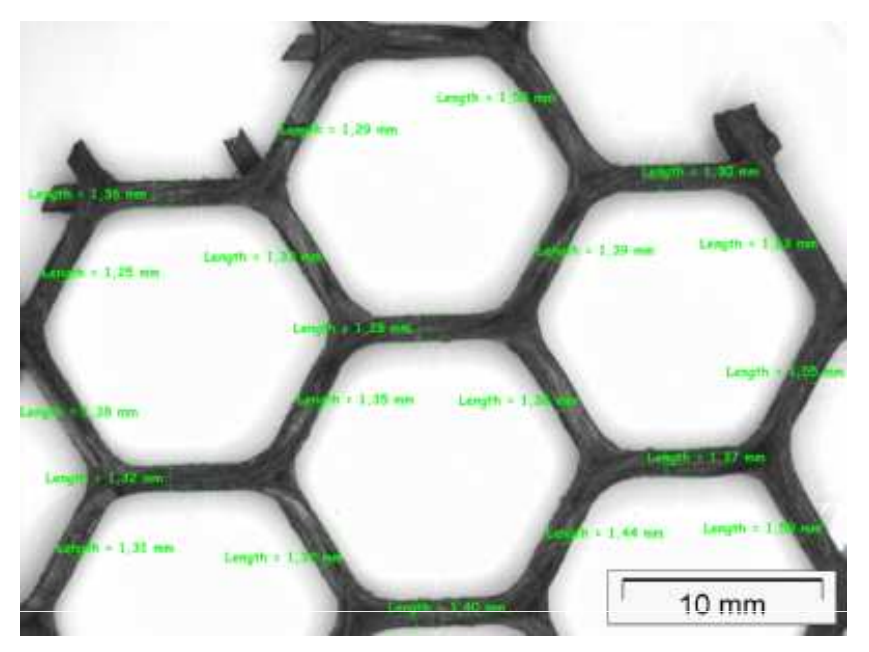

. density $\sim 2.4$ fibers $(\mathrm{V} \%) \sim 30$

\begin{tabular}{|l|c|}
\hline Wall thickness & Target: $\mathbf{1 . 3} \mathbf{~ m m}$ \\
. minimum & 1.25 \\
. maximum & 1.63 \\
. average & $\mathbf{1 . 3 9}$ \\
. standard deviation & 0.1 \\
\hline & \\
\hline Distance between $\mathbf{2}$ /I walls & Target: $\mathbf{1 2 . 7} \mathbf{~ m m}$ \\
\hline . minimum & 12.57 \\
. maximum & 12.95 \\
. average & $\mathbf{1 2 . 8 4}$ \\
. standard deviation & 0.12 \\
\hline
\end{tabular}

MIN口S 


\section{Cla 3-PIN / GENERAL MANUFACTURING}

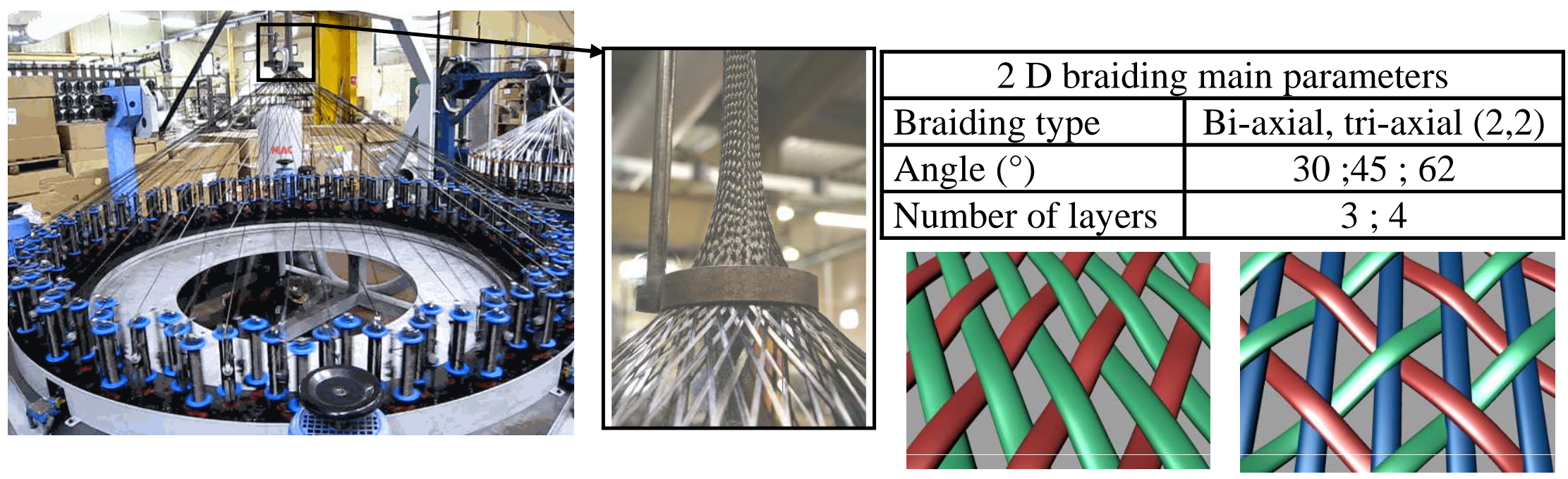

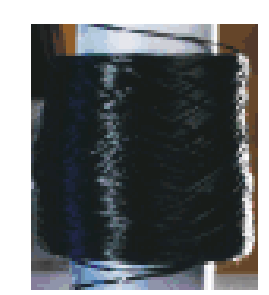

$\mathrm{SiC}$ fibers
Braiding on a substrate

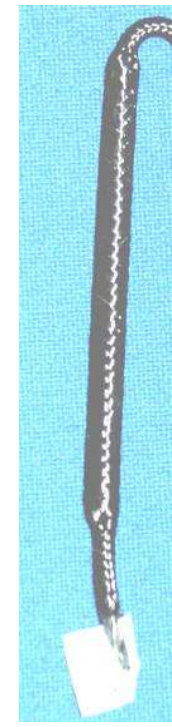

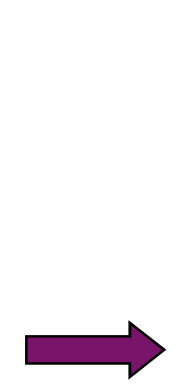

Insertion in a carbon tool

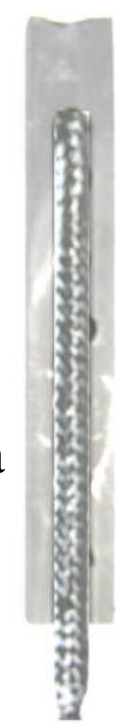

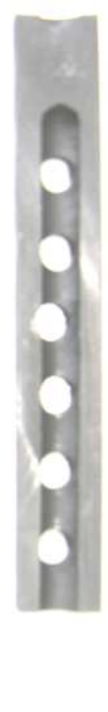

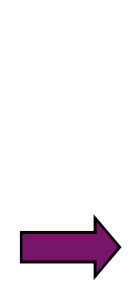

CVI ; removing the substrate

$\because$ MINDS

Workshop Materials Innovation for Nuclear Optimized Systems 


\section{Cea NEW PROCESS FOR PIN CLOSURE}

$\underline{\text { Regular braiding }}$

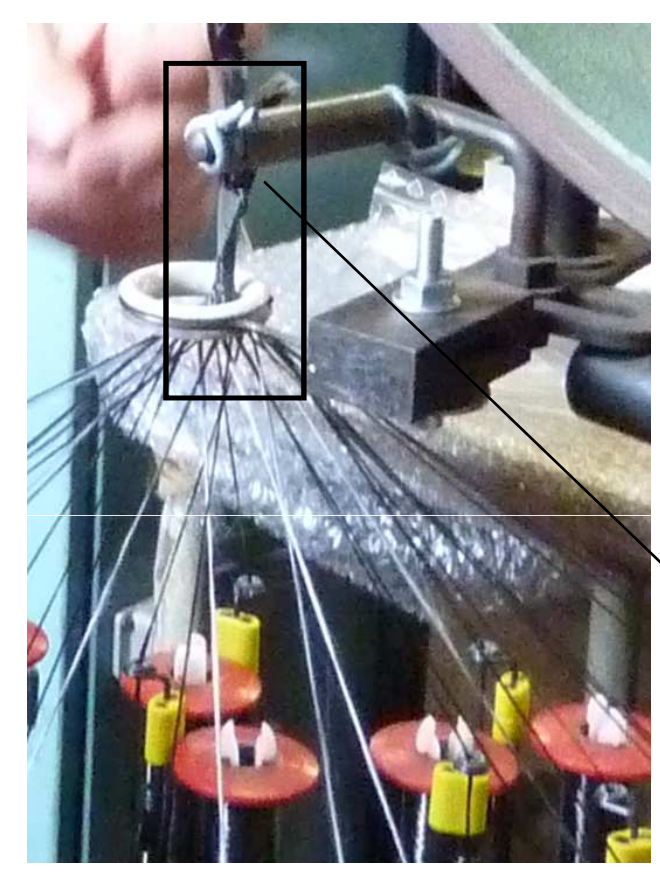

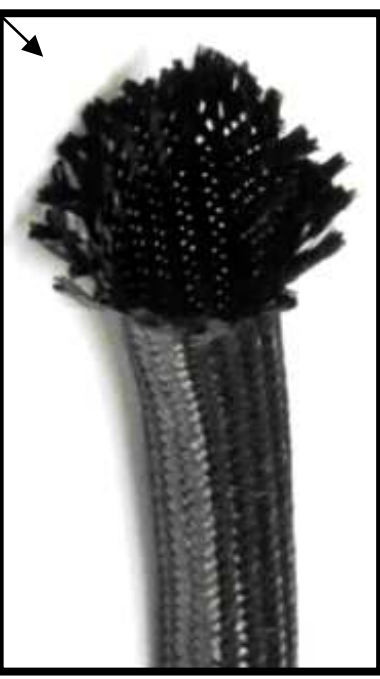

$\because$ MINaS
Braiding with a closed extremity
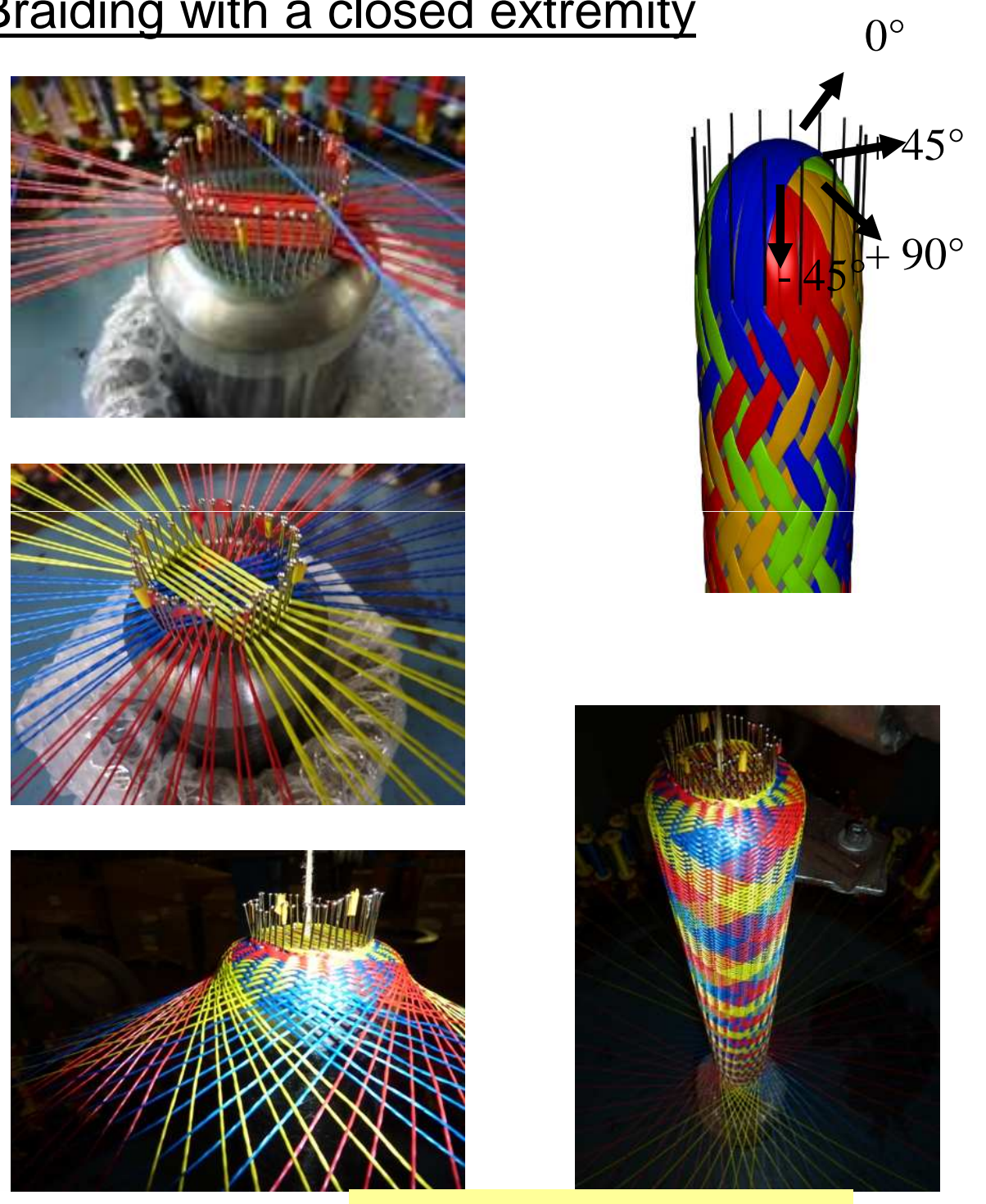

CEA Patent EP2010/067736

$8 / 17$ 


\section{Cea PIN CLOSURE RESULTS}

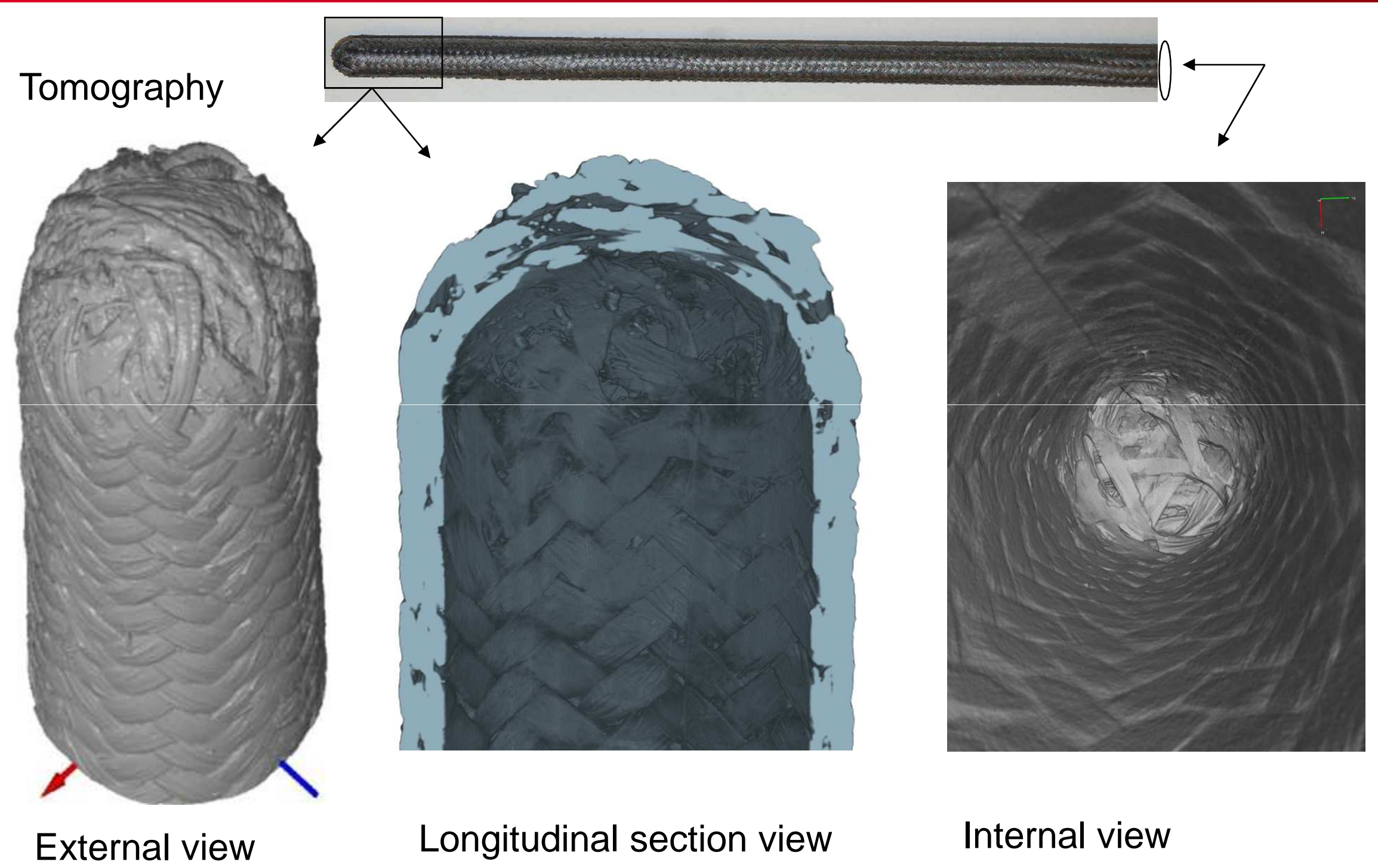

$\because$ MINOS 


\section{PIN CHARACTERISTICS / Internal part}

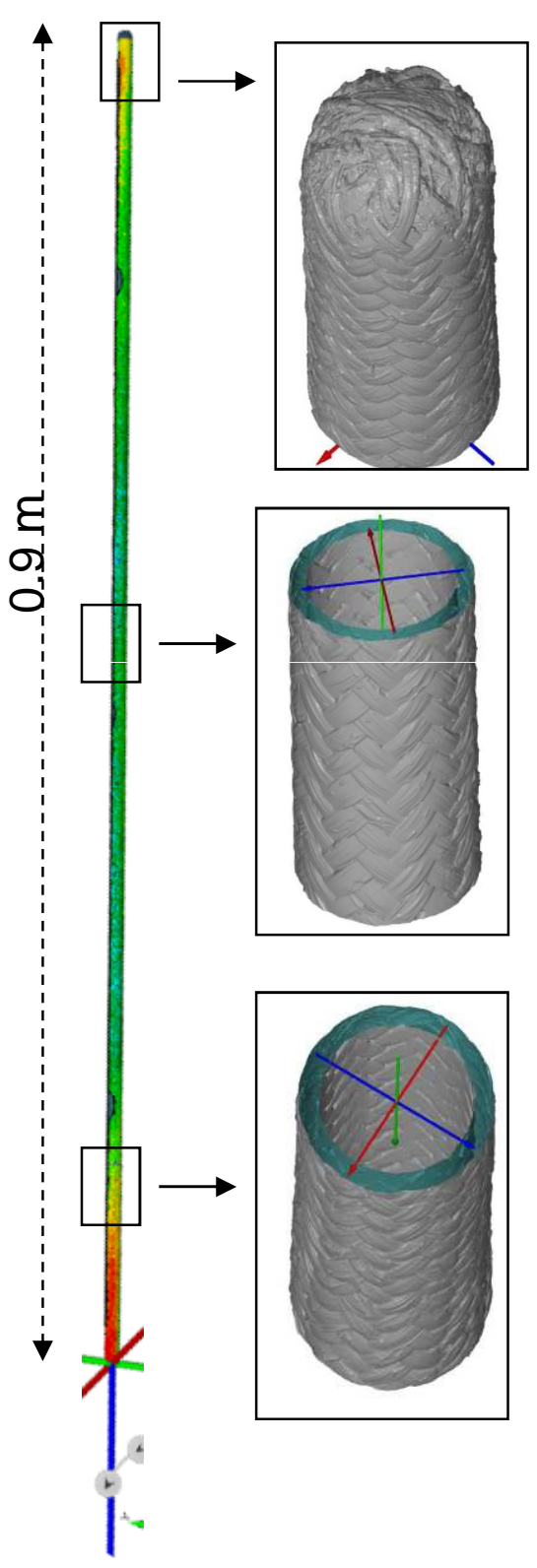

Internal diameters

(mm)

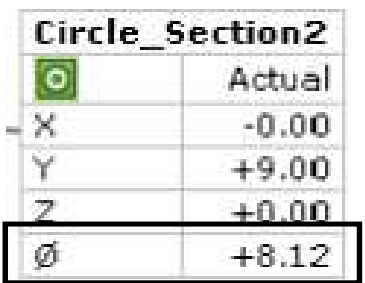

Circle_Section2

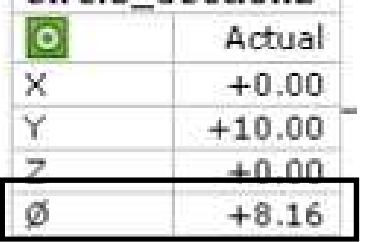

Circle_Inter_Section2

a) Actual
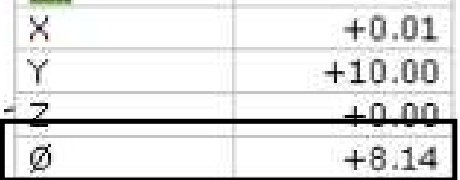

$+8.14$

$\because$ MINOS
$\mathrm{SiC}$ CVD on $\mathrm{C}$ rod
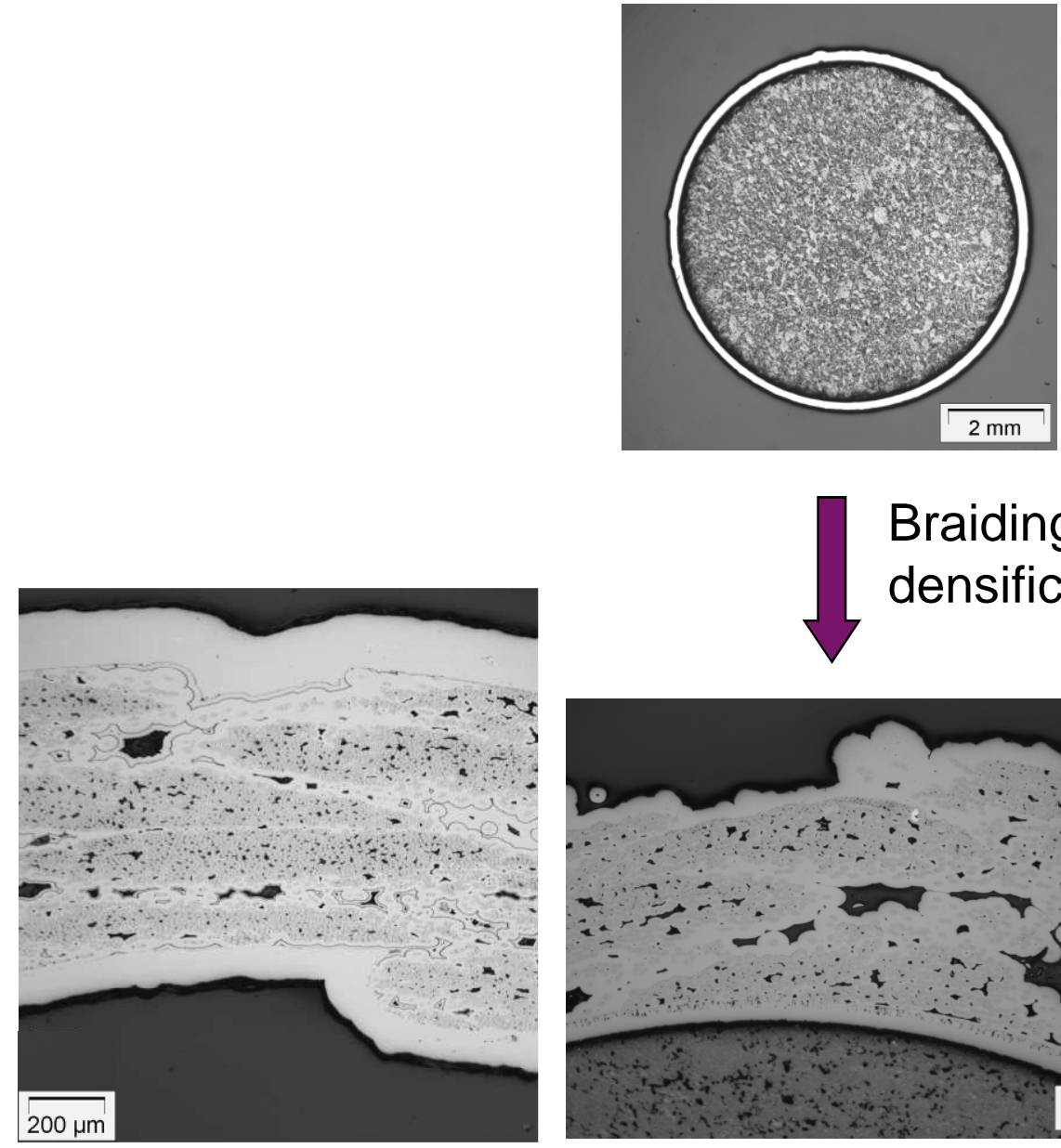

Braiding, densification

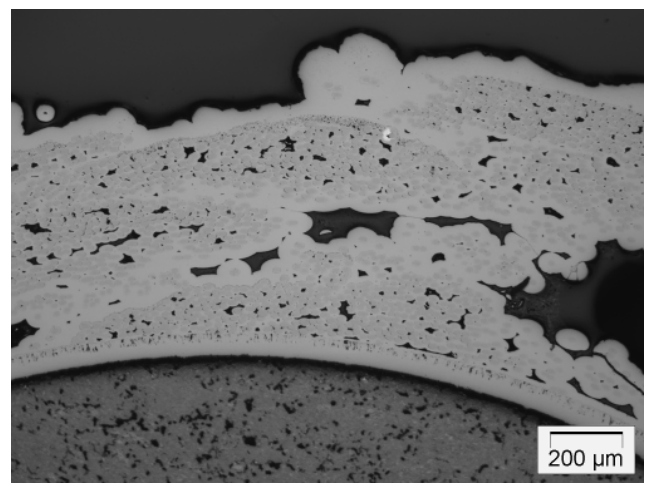

Internal roughness

$$
\mathrm{Ra}=26 \mu \mathrm{m}
$$




\section{PIN CHARACTERISTICS/External surface}

Samples: $10 \mathrm{~cm}$ length pin (inner diameter : $7.0 \mathrm{~mm}$; external : $9.0 \mathrm{~mm}$ )

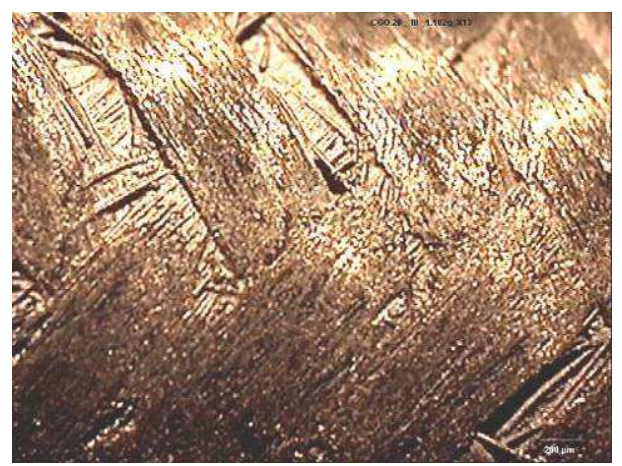

Pin machining

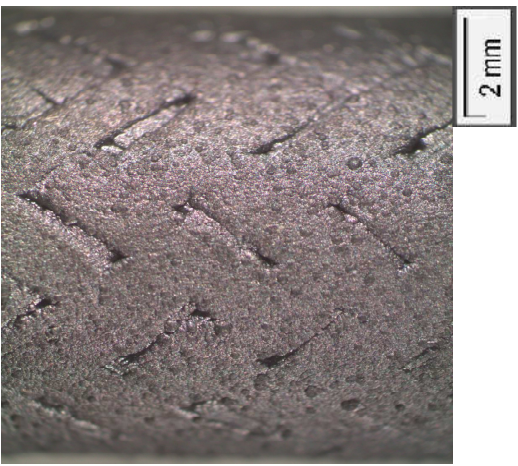

Machining + CVD Smoothness step + machining

Control of the diameter

\begin{tabular}{|c|c|c|c|c|c|c|}
\hline \multirow{2}{*}{$\begin{array}{l}\text { Ф external } \\
(\mathrm{mm})\end{array}$} & \multirow{2}{*}{$\begin{array}{c}\text { Before } \\
\text { machinind }\end{array}$} & \multicolumn{5}{|c|}{ After machining } \\
\hline & & Plane A & Plane B & Plane C & Plane D & Plane E \\
\hline $\begin{array}{l}\text { HNS, } 4 \text { L bi- } \\
\text { axial, } 45^{\circ}\end{array}$ & $10,1+-0,1$ & 8,98 & 8,99 & 8.98 & 8,97 & 8,99 \\
\hline $\begin{array}{l}\text { SA3, } 3 \text { L bi- } \\
\text { axial, } 62{ }^{\circ}\end{array}$ & $10,1+-0,1$ & 8,96 & 8,93 & 8,96 & 8,96 & 8,96 \\
\hline
\end{tabular}

\begin{tabular}{|c|c|c|c|c|}
\hline \multirow{3}{*}{ Straightness (along a line) } & Tube (after machining) & $\begin{array}{c}\text { General } \\
\text { straightness (mm) }\end{array}$ & $\begin{array}{l}\text { Local straightness } \\
(\mathrm{mm})\end{array}$ & \multirow{3}{*}{$\begin{array}{l}\text { Straightness has to be } \\
\text { improved } \\
\text { for } 0.9 \mathrm{~m} \text { long pin }\end{array}$} \\
\hline & HNS, 4 L bi-axial, $45^{\circ}$ & \begin{tabular}{|l}
$<0.03$ \\
\end{tabular} & 0.04 & \\
\hline & SA3, 3 L bi-axial, $62^{\circ}$ & $<0,04$ & 0,08 & \\
\hline
\end{tabular}

\begin{tabular}{|c|c|c|}
\hline \multirow{2}{*}{ Roughness } & $\mathrm{Ra}^{\prime}(\mu \mathrm{m}) \varnothing$ & $\mathrm{Rz}(\boldsymbol{\mu m}) \circ$ \\
\hline & $10_{\circ}$ & $60_{\circ}^{\circ}$ \\
\hline
\end{tabular}

MIN口S

Workshop Materials Innovation for Nuclear Optimized Systems 


\section{CEA PIN BUFFER CONCEPTION}
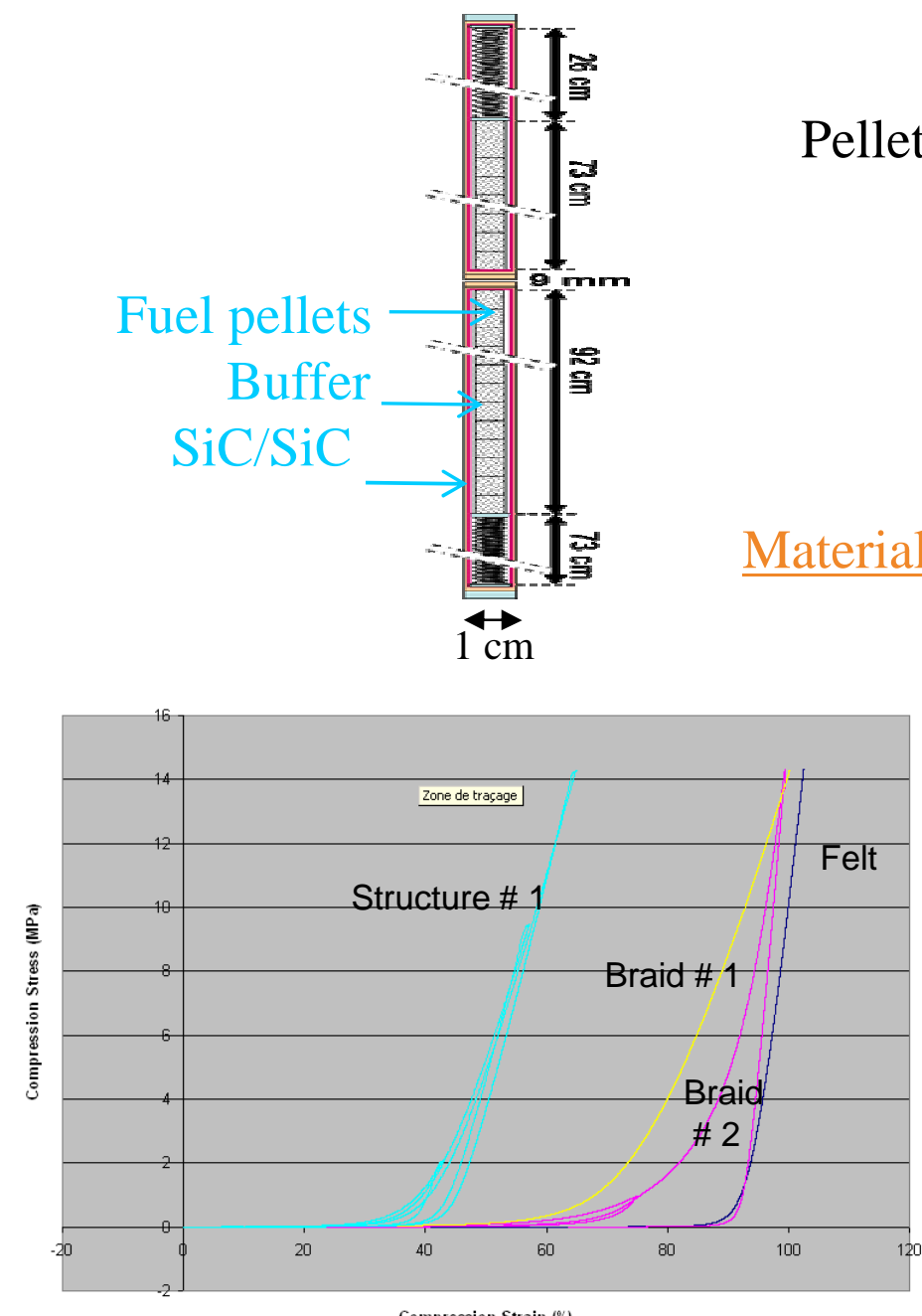

Excellent compressibility up to $\sigma=10 \mathrm{MPa}$
Pellet/clad porous-solid ("buffer") bond

- Thermal conductivity, at high T

- Mechanical protection (PCMI, chips...)

- Pellet/clad centering, FP diffusion barrier

Material: ceramic $(\mathrm{C}, \mathrm{SiC})$ porous structure
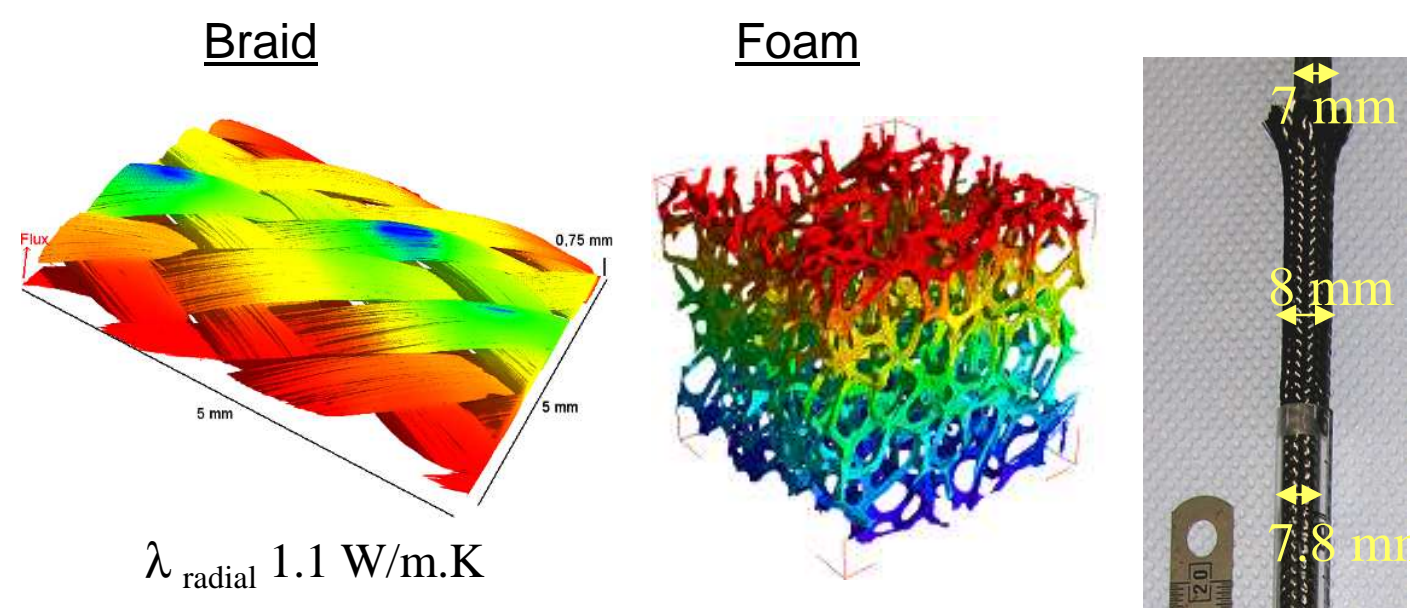


\section{Cea 5- FILM-BOILING FOR HEX. TUBE DENSIF./ GENERALITIES}

CEA process: . high densification rate

$\Longrightarrow$ Hex.Tube

$$
\text { . thick part }
$$
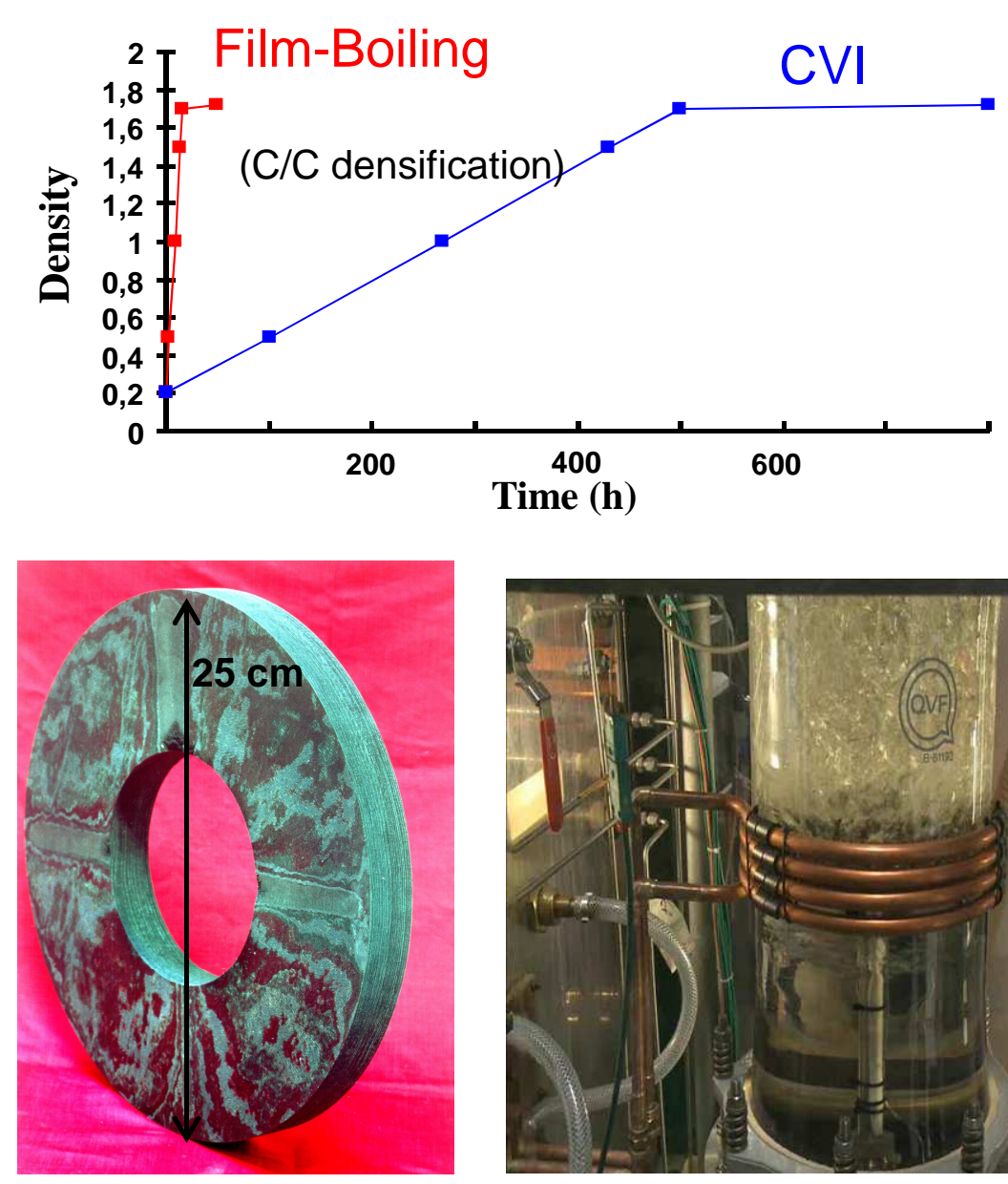

$\mathrm{C} / \mathrm{C}$ brake

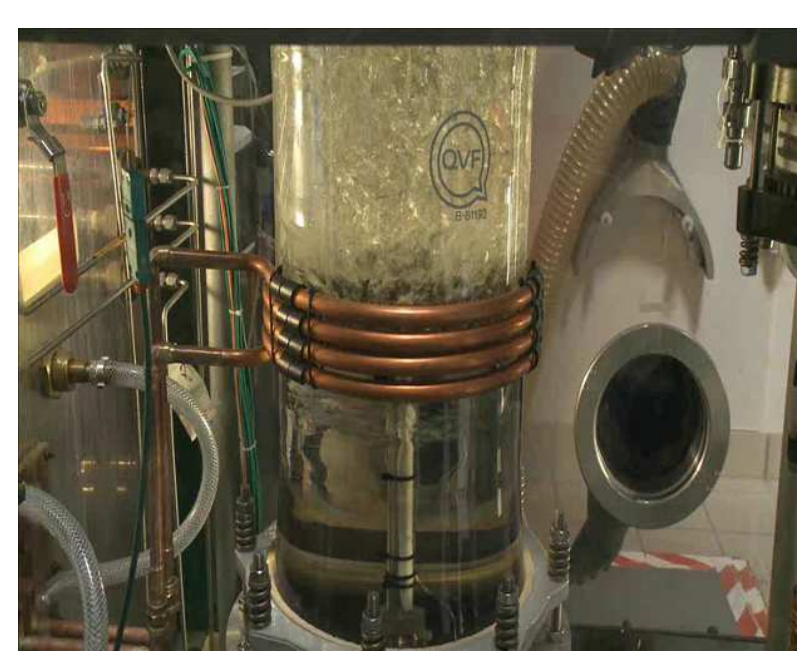

MINDS
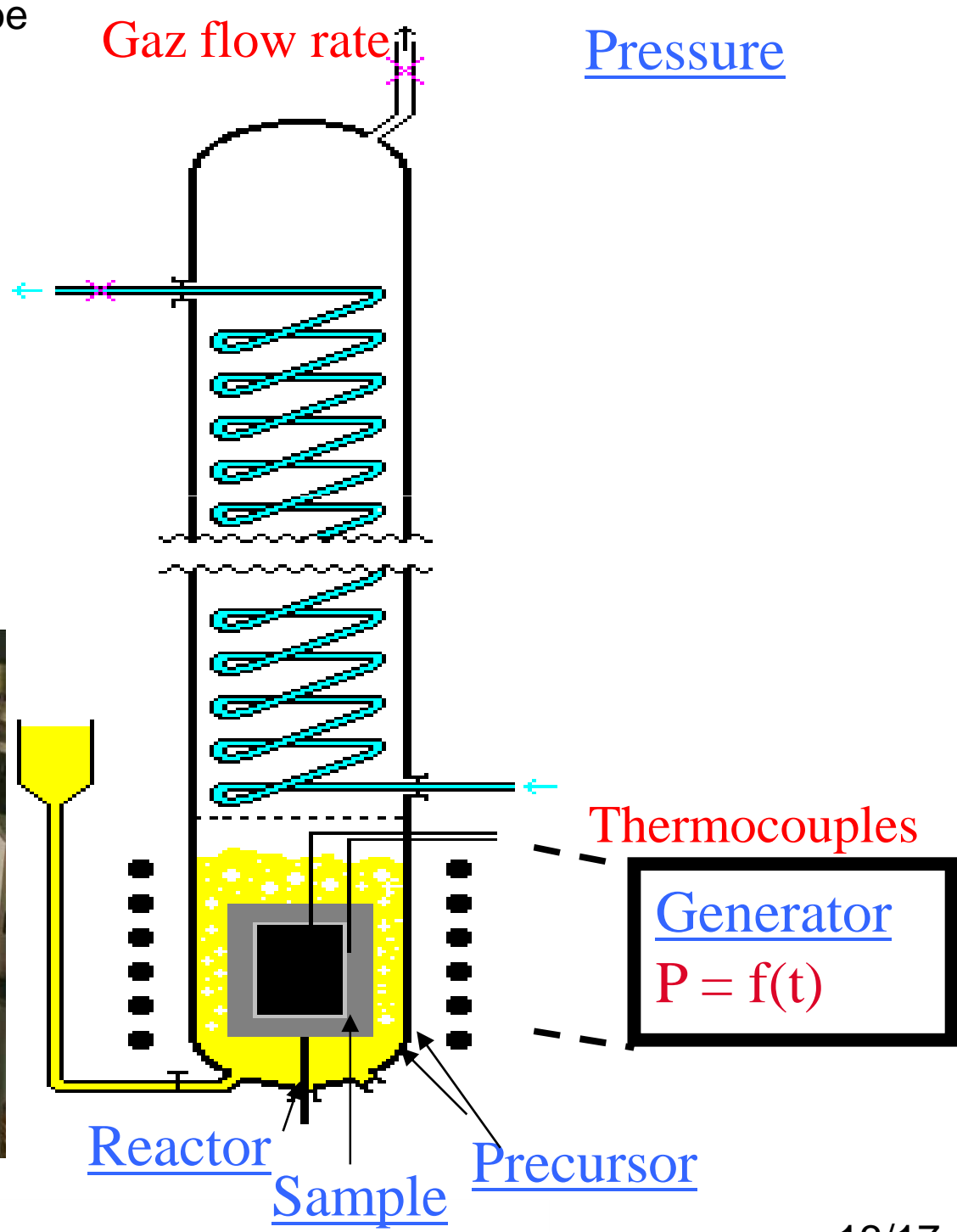

$\underline{\text { Pressure }}$

$13 / 17$ 


\section{STUDIES FOR HEXAGONAL TUBE DENSIFICATION}

$\underline{\text { Parameters }}$

$>$ chemical precursors (MTS, CVD 4000, ...)

$\mathrm{SiCl}_{3} \mathrm{CH}_{3} \longrightarrow(3-\mathrm{x}) \mathrm{SiC}+x \mathrm{C}+x \mathrm{SiCl}_{4}+(3-4 \mathrm{x}) \mathrm{HCl}+2 \mathrm{xH}_{2}$

V densification : $0.1-1 \mathrm{~mm} / \mathrm{h}\left(\mathrm{T}<1000{ }^{\circ} \mathrm{C}\right)$

structures, samples configuration, T cycles, ...

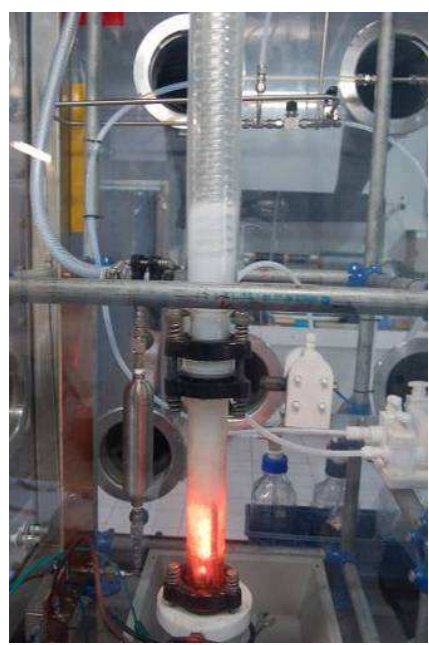

Film boiling apparatus

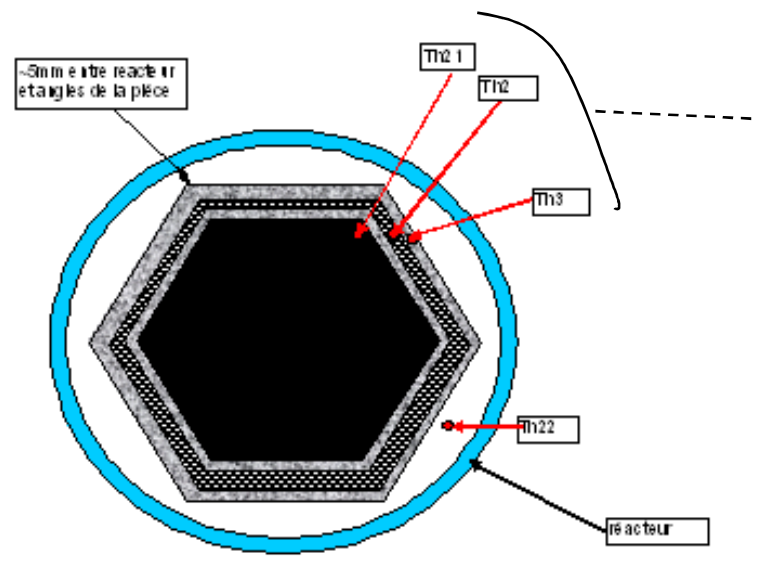

Localization of the thermocouples

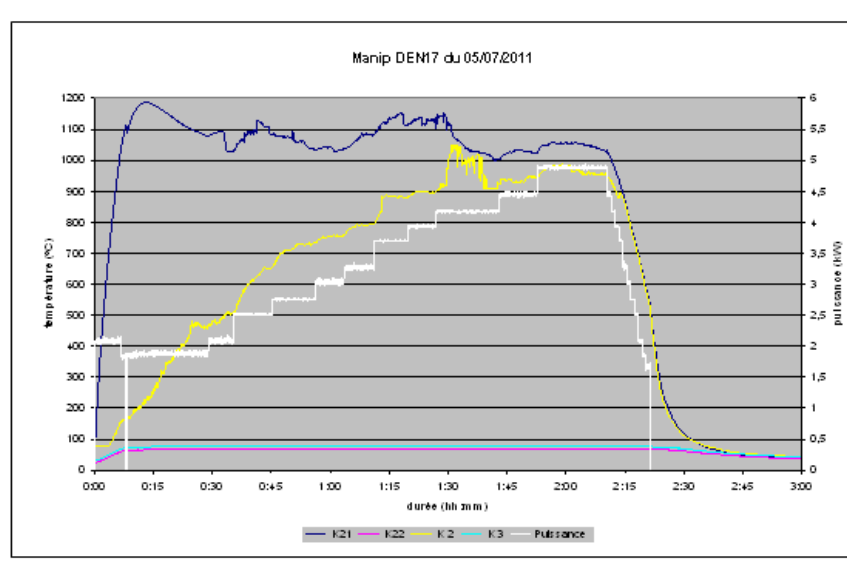

Thermal cycle

MINDS 


\section{Cea H.T DENSIFICATION RESULTS}

$\underline{\text { Felts }}$

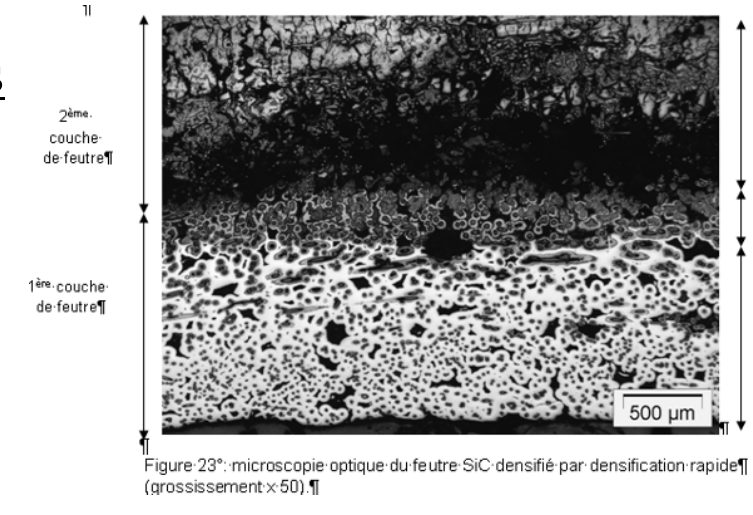

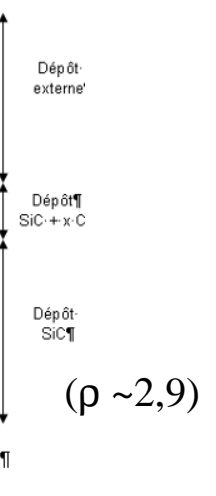

$\underline{\text { Braids }}$
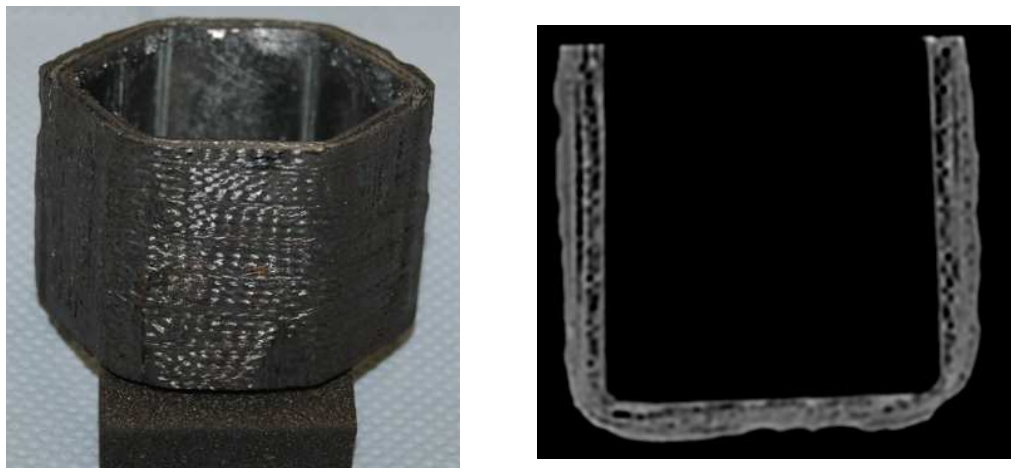

Non crimp fabric (fibers placement)

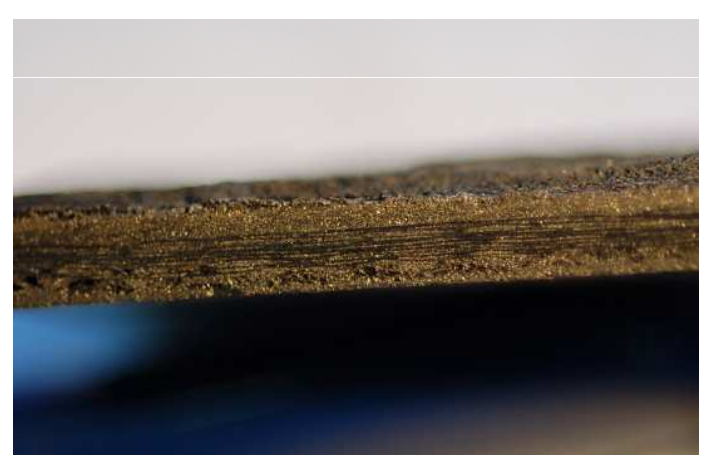

Macroscopic view

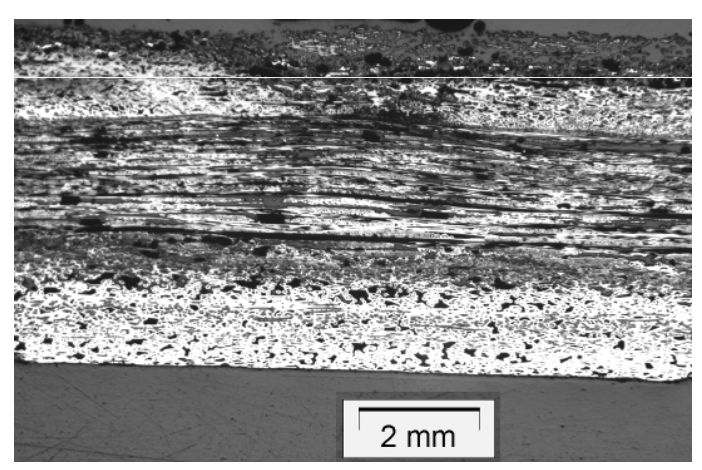

Microstructure view (optical microscopy)

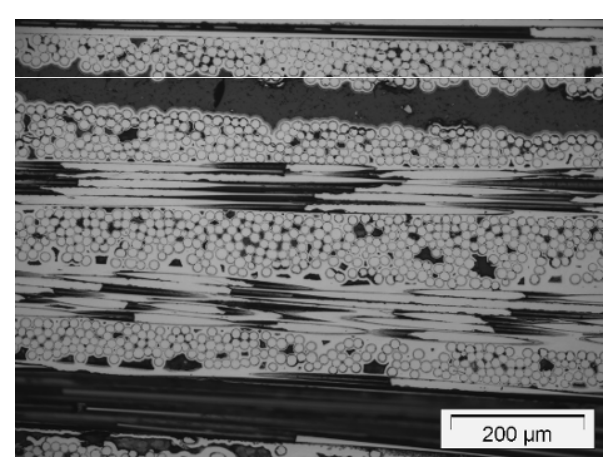

$200 \mu \mathrm{m}$

$\underline{\text { Densification }}$

. C excess : $1-15 \%$ at. 


\section{5- INSULATING SIC COMPOSITES (HTR Hot gas duct application)}

Specifications : $\lambda<0.5 \mathrm{~W} / \mathrm{m} . \mathrm{K}$, for $450^{\circ} \mathrm{C}<\mathrm{T}<850^{\circ} \mathrm{C}$ and $\mathrm{P} \sim 70$ bar

\section{1- Low conductivity matrix}

\begin{tabular}{|l|c|}
\hline Material & $\begin{array}{c}\text { Diffusivity } \\
\left(10^{-5} \mathrm{~m}^{2} \cdot \mathrm{s}^{-1}\right)\end{array}$ \\
\hline Tyranno SA3 & 0.9 \\
\hline CVI matrix & 1.3 \\
\hline Film Boil. matrix (b) & 0.1 \\
\hline
\end{tabular}

Thermal diffusivity of $\mathrm{SiC}$ fibres and $\mathrm{SiC}$ matrices

\section{2- Low density composite}

\begin{tabular}{|c|c|c|}
\hline $\begin{array}{c}\text { SiC/SiC density } \\
\left(\mathrm{g} / \mathrm{cm}^{3}\right)\end{array}$ & $\begin{array}{c}\text { Diffusivity } \\
\left(10^{-7} \mathrm{~m}^{2} \cdot \mathrm{s}^{-1}\right)\end{array}$ & $\begin{array}{c}\text { Transversal conductivity } \\
(\mathrm{W} / \mathrm{m} . \mathrm{K})\end{array}$ \\
\hline 0.26 & 1.5 & 0.03 \\
\hline 0.53 & 3.1 & 0.12 \\
\hline
\end{tabular}

Thermal diffusivity and conductivities of low density $\mathrm{SiC} / \mathrm{SiC}$

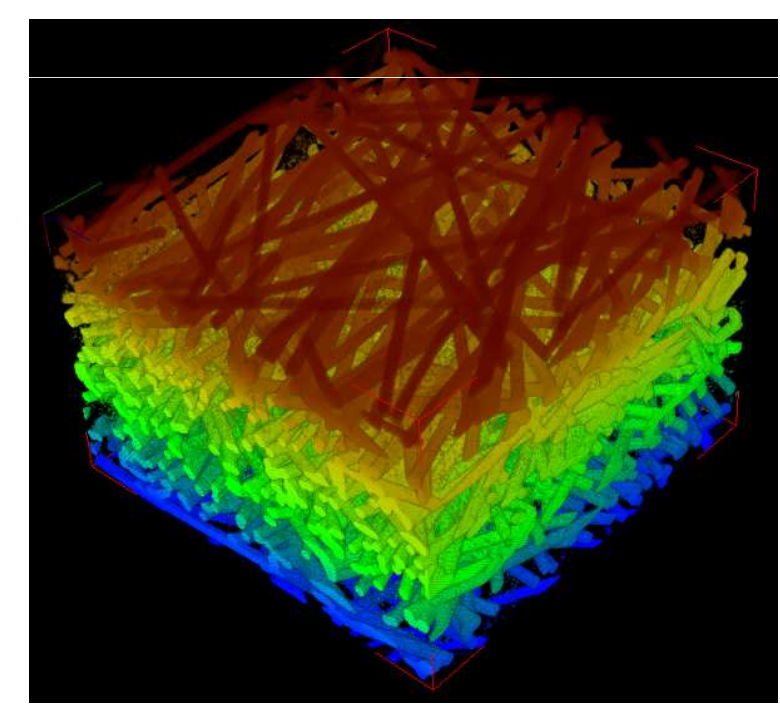

Simulated $\mathrm{T}$ in a low density $\mathrm{SiC} / \mathrm{SiC}$

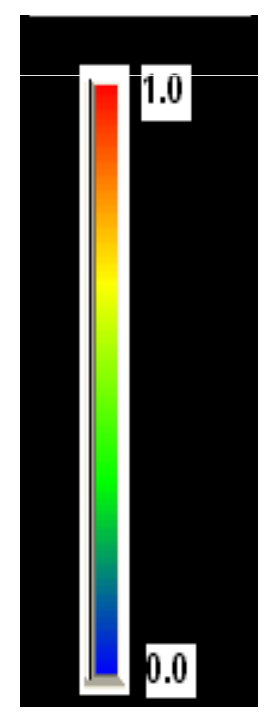

$\mathrm{T}$

(Normalized)

MINDS

Workshop Materials Innovation for Nuclear Optimized Systems 


\section{cea 6- CONCLUSION}

- New materials and processes

- Characterization and simulation of the fibrous architectures and composites

Transposition of the knowledge to other fields :

aeronautic, spatial, energy

- Continuation

. film-boiling, for hexagonal tube

. characterizations (thermal, mechanical) 


\section{Thank you for your attention}

